\title{
Sound Power Characteristics of Chinese Traditional Wind Instrument Qudi
}

\author{
Jianzhen Qiu ${ }^{1,2,{ }^{*}, \text { Shuoxian } \mathrm{Wu}^{1,2} \text {, Yuezhe Zhao }}{ }^{1,2}$, Hong Huang ${ }^{3}$, Liling $\mathrm{Wu}^{3}$ \\ ${ }^{1}$ School of Architecture, South China University of Technology, Guangzhou, China \\ ${ }^{2}$ State Key Laboratory of Subtropical Building Science, South China University of Technology, Guangzhou, China \\ ${ }^{3}$ Musicology Department of Xinghai Conservatoire of Music, Guangzhou, China
}

Email address:

jzqiu@scut.edu.cn (Jianzhen Qiu)

${ }^{*}$ Corresponding author

\section{To cite this article:}

Jianzhen Qiu, Shuoxian Wu, Yuezhe Zhao, Hong Huang, Liling Wu. Sound Power Characteristics of Chinese Traditional Wind Instrument Qudi. International Journal of Architecture, Arts and Applications. Vol. 7, No. 1, 2021, pp. 8-15. doi: 10.11648/j.ijaaa.20210701.12

Received: January 21, 2021; Accepted: January 28, 2021; Published: February 2, 2021

\begin{abstract}
The standards for design and evaluation of Chinese concert halls have followed that of western music and western concert halls all the time. In recent years, studies on the sound characteristics of Chinese traditional musical instruments have been conducted. Wind instrument is an important type of traditional national musical instruments of China. The Chinese flute (Di) is the most representative one among them, the oldest type with a history almost 9000 years, and it is still one of the most widely used instruments now. So the study of Qudi (a main kind of $\mathrm{Di}$ ) can be seen as a representative research work of traditional national wind instruments of China. The measurement presents the sound power level, dynamic range and frequency characteristics of Qudi when single notes, a music scale and a typical melody are performed at various dynamics. This is the first time a research measures the sound power of Qudi by multi-channel real-time analysis method in a reverberation room according to ISO and Chinese national standards. It shows that, Qudi has higher sound power level and a limited dynamic range when compared with Chinese traditional stringed and plucked instruments. The main energy radiation of Qudi is in the alto (middle) range and soprano (high) range. Here, we use sound power level of the music scale performed at forte dynamic as the representative value of Qudi's SWL, and it is $96.2 \mathrm{~dB}$.
\end{abstract}

Keywords: Traditional Musical Instrument, Reverberation Room Method, Sound Power Level, Dynamic Range, Frequency Characteristics

\section{Introduction}

Wind instruments as an important kind of traditional instruments in China appeared very early in the Chinese history. The oldest ancient musical instrument still in existence today is "Wuyang Jiahu Bone Flute". According to archaeologists, it appeared in the early period of the Neolithic China about 9000-7800 years ago [1]. Dizi (the Chinese flute) has always been regarded as a representative of Chinese national wind instruments. Since the beginning of the Spring and Autumn Period, it has played a significant role in bands, and is widely used in the performance of Chinese folk music, opera, folk dance music and modern music. The timbre of Dizi is unique, flexible and changeable, strong in penetrating power and rich in expressiveness. In addition to solo, Dizi often leads and accompanies in Chinese national orchestras. It can also produce various vivid sounds in nature, such as birdsong, sounds of running water, wind and rain.

Most of Dizi bodies currently in use are made of bamboo tubes, so Dizi is also known as "Zhudi", the bamboo flute. It is cylindrical in shape and hollow in the inner bore. The tube body has blowing holes, membrane holes and several sound holes as shown in Figure 1. There are two types of Dizi commonly used in China: Qudi and Bangdi. Qudi is mostly used in southern China, with a mellow, rich and gentle timbre; comparatively, Bangdi is mainly used in the north, with much high and bright timbre. 


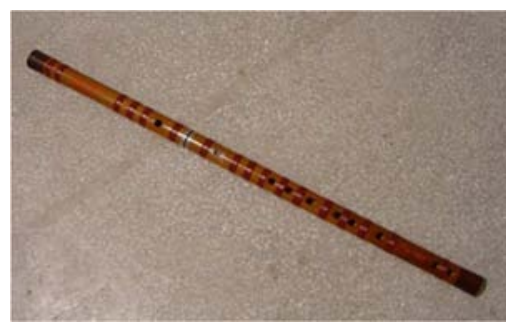

Figure 1. Qudi.

This paper introduces the systematic measurement of the sound power of Qudi according to international and Chinese national standards. In a reverberation room, two well-experienced musicians performed single notes, a music scale, and a typical melody at pianissimo, mezzo-piano, forte and fortissimp ( $p p, m p, f, f f)$ dynamic markings respectively in a normal playing posture, then the sound power level (SWL), dynamic range and frequency characteristics of Qudi at various dynamics are obtained.

In acoustic research and practice, sound power is an important parameter of sound source. It is not only a significant indicator of sound source in the application of sound insulation; in any case, in the judgment of the quality and characteristics of a musical instrument, the radiated sound power is also an important factor. In addition, there are many practical meanings to learn the sound radiation of musical instruments accurately: in terms of hall acoustic quality research and application, sound power helps people gain better access to the total sound power of the playing bands, so as to equip different halls with appropriate band forms and number of musicians to achieve the preferred loudness. Since the 1960s, studies on western musical instruments have been carried out in western countries, including the measurements of the sound power of major western string and wind instruments [2-6]. According to J. Meyer and J. Angster's suggestions based on the sound power testing of violin, the reverberation room method is currently the best for measuring sound power of musical instruments [7]. In recent years, more attention have been paid to the studies of traditional musical instrument's characteristics in China, and the authors of this research have also conducted much research to investigate the SWLs of typical Chinese traditional instruments [8-11], which lays a solid foundation for this further exploration.

\section{Measurement}

The measurement was conducted in a reverberation room which has a square plan and an effective volume of about $200 \mathrm{~m}^{3}$. There are some cylindrical diffusers placed along two adjacent walls, and also some diffusers hung from the ceiling. The lower background noise of the room conforms to the NR15 [12]. The reverberation time of each frequency band is longer than the ratio of the volume to the surface area of the room, which meets the Chinese GB6881-86 test room standard. The cut-off frequency of the room is within $100 \mathrm{~Hz}$, covering the main sound frequency bands of the measured instruments. This reverberation room meets the requirements of HOKLAS (The Hong Kong Laboratory Accreditation Scheme), ISO and ASTM (American Society for Testing and Materials) standards.

The measurement was carried out in accordance with the standards of IOS and GB6881-86. Normally the standard GB6881-86 is applicable to steady sound sources, but according to Meyer and Angster's suggestions based on their SWL measuring of violin, the change of sound source location only causes a little effect on the measuring results [7], so the location of sound sources remained unchanged in this research. The equipment for the measurement included four channels recording the signals simultaneously: a Nor118 sound level meter with a N1225 microphone (point A), a B\&K2260D sound investigator with a B\&K4189 microphone (point $\mathrm{C}$ ), and a $\mathrm{B} \& \mathrm{~K}$ two-channel PULSE3560C system with two B\&K4189 microphones (point $\mathrm{B}$ and point D). The performer was located at the center of the room, facing the middle of the line connecting points $\mathrm{B}$ and $\mathrm{C}$. Four microphones with a height of $1.5 \mathrm{~m}$ were evenly distributed on a circle with a radius of $2.0 \mathrm{~m}$ around the performer. The distance between two adjacent microphones and each microphone to the wall of the room were more than $1.7 \mathrm{~m}$. See Figure 2.

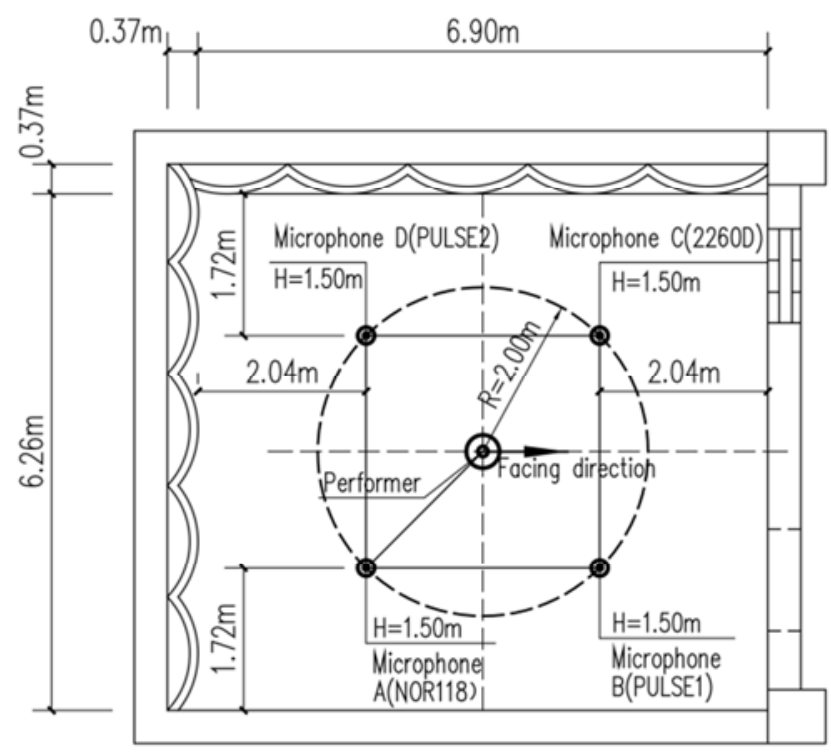

Figure 2. Measurement diagram in the reverberation room.

For each measurement, the sound pressure levels of $1 / 3$-octave bands with a center frequency of $100 \mathrm{~Hz}-10000 \mathrm{~Hz}$ were recorded and analyzed simultaneously through four channels. After they were averaged, the SWL of the $1 / 3$-octave band was calculated according to the national standard GB6881-86, and then the total SWL was achieved. At last, the test results of the two instruments were averaged to obtain the representative SWL and dynamic range of Qudi.

In this research, two well-experienced national musicians were invited to play respectively the same contents on Qudis used in their daily performances. Both performers are male, 
with 40 years (Qudi I) and 13 years (Qudi II) of playing experience, and both the two Qudis have been used for about two years. Both performances were in a sitting position, and the pitch of each instrument was adjusted with a professional tuner before the measurement to guarantee that the pitch frequency of the note $\mathrm{a}^{1}$ was $440 \mathrm{~Hz}$. In order to ensure that the playing forces and habits were much close to their usual performances, they had enough practice in the reverberation room before each measurement until they were fully adapted to the environment. See Figure 3.

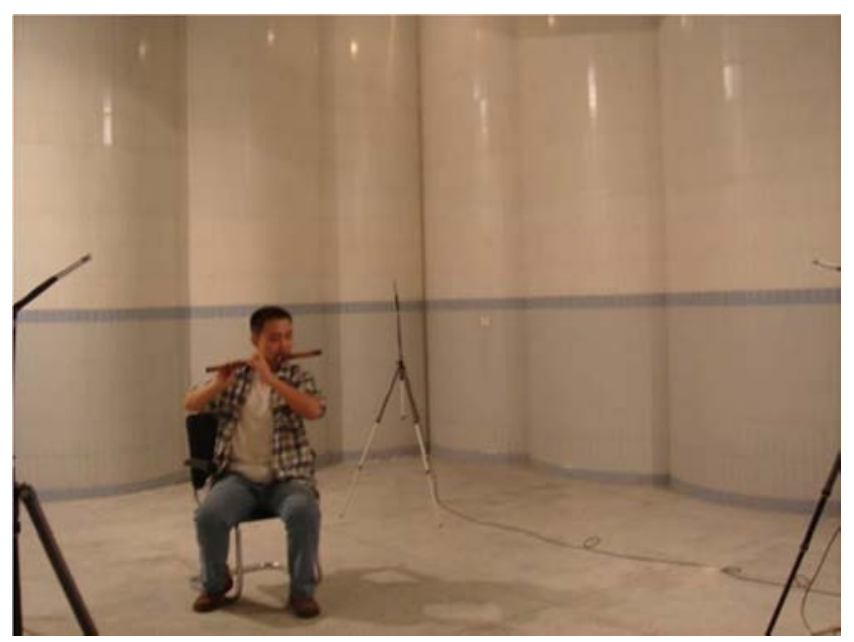

Figure 3. The posture of performing Qudi.

The contents performed for each round of measurement are as follows:

(1) An extract of "Molihua" (Jasmine Flower), a world famous Chinese folk music. Starting from the opening bar, it was played for a recording period of 20 seconds under four dynamic markings ( $p p, m p$, $f$ and $f f$ ).
(2) The music scale $g^{1} \sim g^{3}$, a common range of Qudi. It was performed for a recording period of 8 seconds, covering more than one complete scale, and at a speed of two to three notes per second, under the dynamics of $p p, m p, f$ and $f f$, allowing the performer to breathe once.

(3) $a^{1}, a^{2}$, and $a^{3}$, three representative single notes from the bass, alto and soprano of Qudi's common range. $\mathrm{a}^{1}$ and $\mathrm{a}^{2}$ were played for a recording period of 4 seconds under the dynamics of $p p, m p, f$ and $f f$. But considering the performance characteristics of qudi, $\mathrm{a}^{3}$ was only performed at the dynamics of $m p, f$ and $f f$. The musicians should play in one breath and without any stop.

The requirements for the dynamic markings of the performers are as follows. $P p$ stands for a soft performance, which requires performers to produce clear sounds and unexhausted tones; $\mathrm{mp}$ means a moderately soft performance; $f$ refers to play normally loud, and $f f$ stands for playing very loud, meaning performers should use as much strength as possible, but make sure the pitch sound is still correct, pleasing, constant and not rude.

\section{Results}

\subsection{SWL and Its Dynamic Range}

For comparison with western musical instruments, international alphabets were used to mark the notes of tested musical instruments. As is shown in Table 1, the available range of Qudi is from $\mathrm{a}^{1}$ to $\mathrm{d}^{4}$, and its common range is from $\mathrm{a}^{1}$ to $\mathrm{a}^{3}$. Both the performed music scale and three representative notes were selected from this range, as can be seen in Table 2.

Table 1. The available and commonly used register of Qudi.

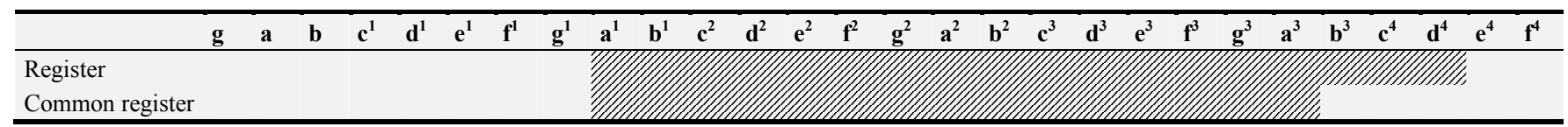

Table 2. The contents performed in Qudi test.

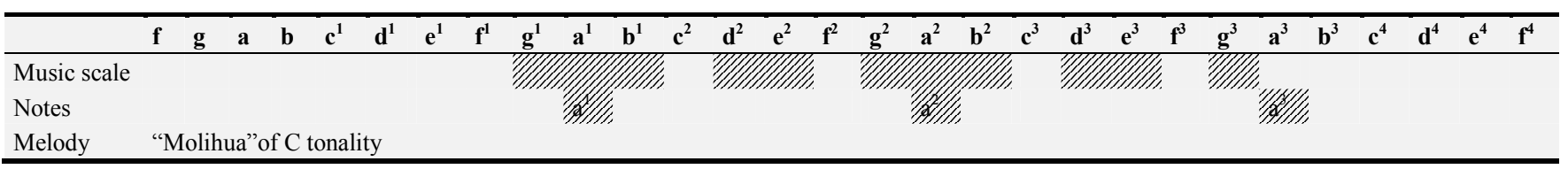

Table 3. SWLs (dB) of Qudi (I, II) when single notes, the music scale and the melody were performed.

\begin{tabular}{|c|c|c|c|c|c|c|c|c|c|c|c|c|c|}
\hline & & \multicolumn{3}{|l|}{$p p$} & \multicolumn{3}{|l|}{$m p$} & \multicolumn{3}{|l|}{$f$} & \multicolumn{3}{|l|}{$f f$} \\
\hline & & I & II & average & I & II & average & I & II & average & I & II & average \\
\hline \multirow{3}{*}{ Notes } & $a^{1}$ & 78.8 & 84.6 & 81.7 & 80.5 & 86.2 & 83.4 & 88.7 & 84.0 & 86.4 & 88.9 & 87.7 & 88.3 \\
\hline & $a^{2}$ & 84.9 & 86.8 & 85.8 & 87.5 & 91.0 & 89.2 & 92.1 & 91.9 & 92.0 & 98.5 & 93.2 & 95.9 \\
\hline & $a^{3}$ & & & & 97.5 & 95.1 & 96.3 & 102.1 & 99.6 & 100.9 & 104.6 & 102.7 & 103.6 \\
\hline \multicolumn{2}{|c|}{ Music scale } & 90.5 & 92.6 & 91.5 & 94.2 & 95.0 & 94.6 & 95.8 & 96.5 & 96.2 & 98.1 & 98.8 & 98.5 \\
\hline \multicolumn{2}{|c|}{ Melody } & 87.9 & 89.3 & 88.6 & 90.8 & 90.4 & 90.6 & 94.0 & 92.6 & 93.3 & 96.9 & 94.6 & 95.8 \\
\hline
\end{tabular}

Table 3 shows SWLs of Qudi I and II when single notes, the music scale and the melody were performed. It can be observed that the SWLs of Qudi were in the range of $78.8 \sim 104.6 \mathrm{~dB}$, and the lowest value of $78.8 \mathrm{~dB}$ appeared when 
$\mathrm{a}^{1}$ was played on Qudi I at $p p$ dynamic, while the highest value of 104.6dB appeared when $\mathrm{a}^{3}$ was played on Qudi I at $f f$ dynamic.

Tables 4 and 5 list the results of Qudi I and II to illustrate their differences in SWL dynamic range and sound quality. The data demonstrate that, compared with Qudi II, Qudi I shows a larger dynamic range in almost all contents performed in the measurement, which means Qudi I can achieve a wider sound span than Qudi II. When the performer played $\mathrm{a}^{2}$ on Qudi I, the dynamic range was $13.6 \mathrm{~dB}$, which is the maximum in the test. When the performer played a ${ }^{1}$ on Qudi II, the minimum dynamic range appeared, which was only $3.1 \mathrm{~dB}$.

Table 6 displays the average SWLs and dynamic ranges of Qudi I and II when three single notes, the music scale and the melody were performed.

Table 4. SWLs and dynamic range (dB) of Qudi I when single notes, the music scale and the melody were performed.

\begin{tabular}{llllll}
\hline & $\boldsymbol{p p}$ & $\boldsymbol{m p}$ & $\boldsymbol{f}$ & $\boldsymbol{f f}$ & Dynamic range \\
\hline $\mathrm{a}^{1}$ & 78.8 & 80.5 & 88.7 & 88.9 & 10.1 \\
$\mathrm{a}^{2}$ & 84.9 & 87.5 & 92.1 & 98.5 & 13.6 \\
$\mathrm{a}^{3}$ & & 97.5 & 102.1 & 104.6 & 7.1 \\
Music scale & 90.5 & 94.2 & 95.8 & 98.1 & 7.6 \\
Melody & 87.9 & 90.8 & 94.0 & 96.9 & 9.0 \\
\hline
\end{tabular}

Table 5. SWLs and dynamic range (dB) of Qudi II when single notes, the music scale and the melody were performed.

\begin{tabular}{llllll}
\hline & $\boldsymbol{p p}$ & $\boldsymbol{m} \boldsymbol{p}$ & $\boldsymbol{f}$ & $\boldsymbol{f f}$ & Dynamic range \\
\hline $\mathrm{a}^{1}$ & 84.6 & 86.2 & 84.0 & 87.7 & 3.1 \\
$\mathrm{a}^{2}$ & 86.8 & 91.0 & 91.9 & 93.2 & 6.4 \\
$\mathrm{a}^{3}$ & & 95.1 & 99.6 & 102.7 & 7.6 \\
Music scale & 92.6 & 95.0 & 96.5 & 98.8 & 6.2 \\
Melody & 89.3 & 90.4 & 92.6 & 94.6 & 5.3 \\
\hline
\end{tabular}

Table 6. The average SWL and dynamic range (dB) of Qudi I and II when single notes, the music scale and the melody were performed.

\begin{tabular}{llllll}
\hline & $\boldsymbol{p p}$ & $\boldsymbol{m} \boldsymbol{p}$ & $\boldsymbol{f}$ & $\boldsymbol{f f}$ & Dynamic range \\
\hline $\mathrm{a}^{1}$ & 81.7 & 83.4 & 86.4 & 88.3 & 6.6 \\
$\mathrm{a}^{2}$ & 85.8 & 89.2 & 92.0 & 95.9 & 10.1 \\
$\mathrm{a}^{3}$ & & 96.3 & 100.9 & 103.6 & 7.3 \\
Music scale & 91.5 & 94.6 & 96.2 & 98.5 & 7.0 \\
Melody & 88.6 & 90.6 & 93.3 & 95.8 & 7.2 \\
\hline
\end{tabular}

\subsection{1/3 Octave Bands SWL Spectra}

Table 7 shows the frequencies of the music scale and single notes. It can be seen that the music scale in this measurement is from $\mathrm{g}^{1}$ to $\mathrm{g}^{3}$, and the frequency range is $392.9 \mathrm{~Hz}$ to $1560 \mathrm{~Hz}$. The frequencies of $\mathrm{a}^{1}, \mathrm{a}^{2}$ and $\mathrm{a}^{3}$ are $440 \mathrm{~Hz}, 880 \mathrm{~Hz}$, and $1760 \mathrm{~Hz}$, respectively, and they are located in the $1 / 3$ octave bands with center frequencies of $400 \mathrm{~Hz}, 800 \mathrm{~Hz}$ and $1600 \mathrm{~Hz}$.

Table 7. Frequencies of the music scale and single notes $(\mathrm{Hz})$.

\begin{tabular}{|c|c|c|c|c|c|}
\hline Music scale & 6 & 68 & $c^{2}$ & $\mathrm{f}^{2}$ & \\
\hline Frequency & 30 & SPI $\$$ & 523.2 & 698.4 & 8 \\
\hline Music scale & 2 & $c^{3}$ & $" 1 / 4$ & & \\
\hline Frequency & 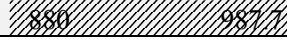 & 1046.5 & N & 18 & 16 \\
\hline
\end{tabular}

Figures 4 and 5 show the SWL spectra in 1/3 octave bands of Qudi I and II when the music scale was performed at four dynamics.

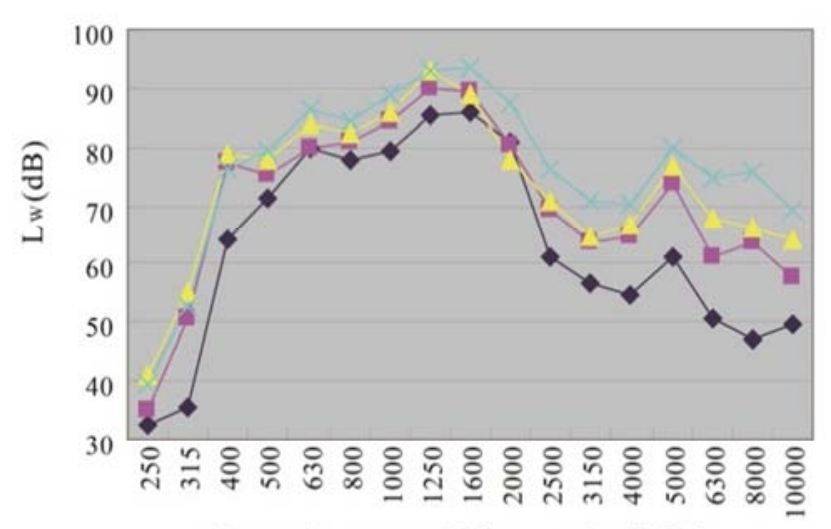

Center frequency of $1 / 3$ octave bands $(\mathrm{Hz})$

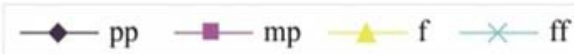

Figure 4. SWL spectra in 1/3 octave bands of Qudi I when the music scale was performed at four dynamics.

Both SWL charts of Qudi I and II show that the SWL decreases rapidly in low frequency bands (i.e., the $1 / 3$ octave bands of the frequency less than $400 \mathrm{~Hz}$ ). What's more, it also decreases obviously in high frequency bands (i.e., the $1 / 3$ octave bands of the frequency greater than $6300 \mathrm{~Hz}$ ), which means, the sound energy radiated by Qudi is mainly in the middle and high frequency bands of $400 \sim 6300 \mathrm{~Hz}$.

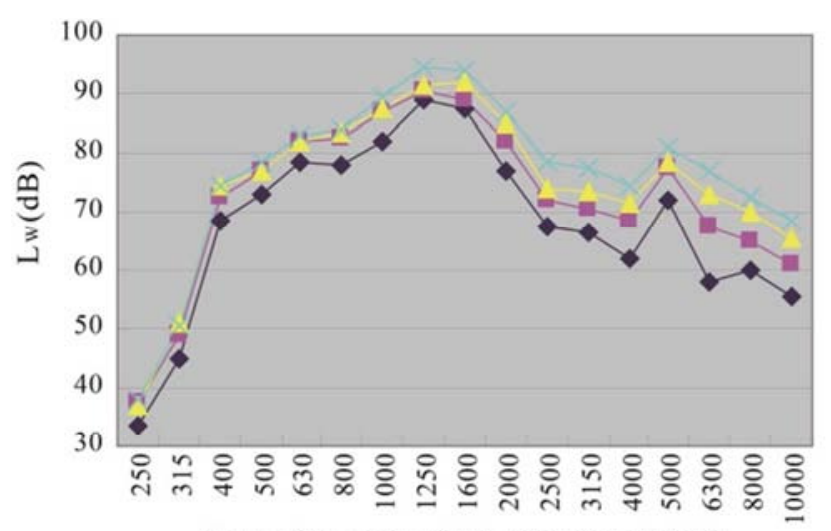

Center frequency of $1 / 3$ octave bands $(\mathrm{Hz})$

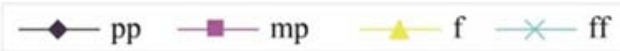

Figure 5. SWL spectra in 1/3 octave bands of Qudi II when the music scale was performed at four dynamics.

Figure 6 reveals the average SWLs in $1 / 3$ octave bands when the music scale was performed on Qudi I and II. It can be seen that at four dynamics, the shape of the sound power spectra in the high frequency bands is completely different 
from that in the low frequency bands.

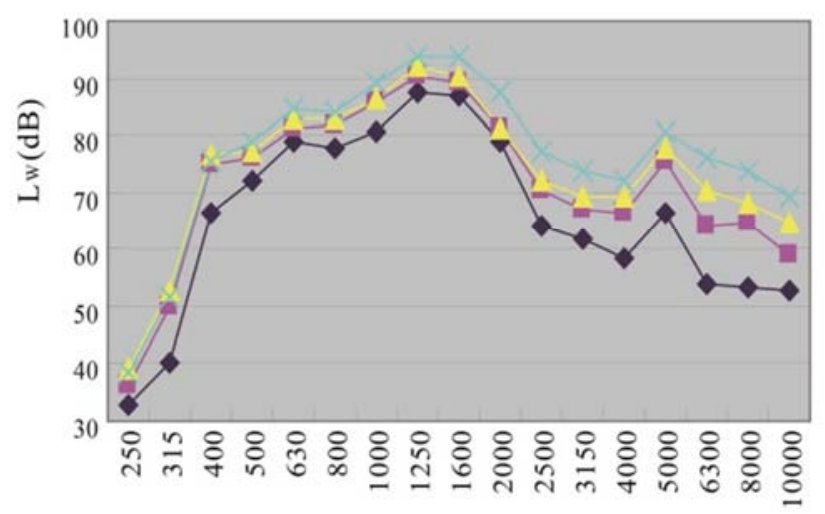

Center frequency of $1 / 3$ octave bands( $\mathrm{Hz})$

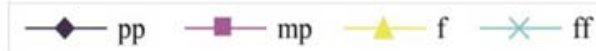

Figure 6. Average SWL spectra in 1/3 octave bands of Qudi I and II when the music scale was performed at four dynamics.

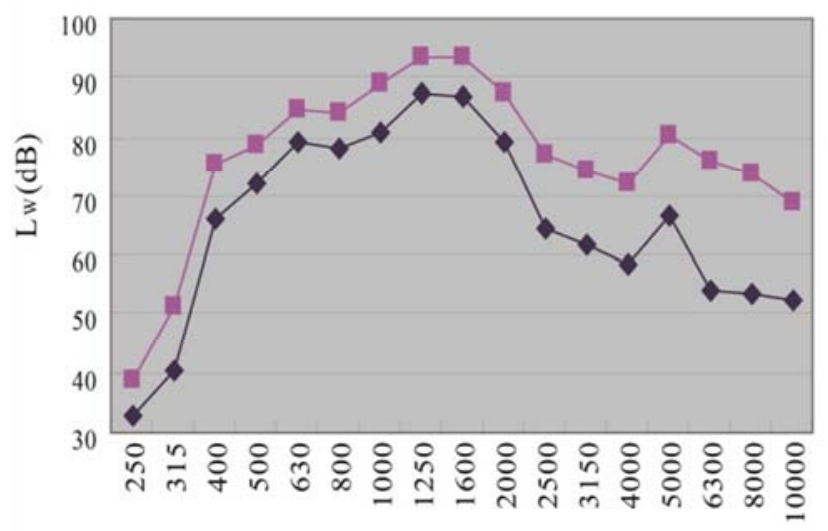

Center frequency of $1 / 3$ octave bands( $\mathrm{Hz})$

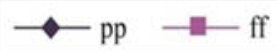

Figure 7. SWL spectra in 1/3 octave bands of Qudis (I, II) when performing the music scale at pp and ff dynamics.

Further analysis on the differences in SWLs of four dynamics in each frequency band indicates that in $1 / 3$ octave bands frequencies of $250 \sim 2000 \mathrm{~Hz}$, all differences in SWLs of $p p$ and $f f$ dynamics are between 6.3 to $9.0 \mathrm{~dB}$, except for the differences of $11.1 \mathrm{~dB}$ and $5.4 \mathrm{~dB}$ occurring at $315 \mathrm{~Hz}$ and $630 \mathrm{~Hz}$ respectively. Besides, starting from $2500 \mathrm{~Hz}$, the SWL difference between $p p$ and $f f$ dynamics increased significantly, with the maximum of $21.9 \mathrm{~dB}$ appearing in the $1 / 3$ octave band of $6300 \mathrm{~Hz}$. The characteristics of Qudi's sound power spectra may be related to the pronunciation mechanism of some wind instruments, which shares similarities with the test results of some western musical instruments, such as oboe and horn [4, 13].

Figure 7 presents the average SWLs in $1 / 3$ octave bands when the two Qudis were performed at $p p$ and $f f$ dynamics respectively. It reveals when center frequencies in $1 / 3$ octave bands exceed $5000 \mathrm{~Hz}$, the charts at $f f$ and $p p$ dynamics decrease at a gradient more than $10 \mathrm{~dB} /$ oct.

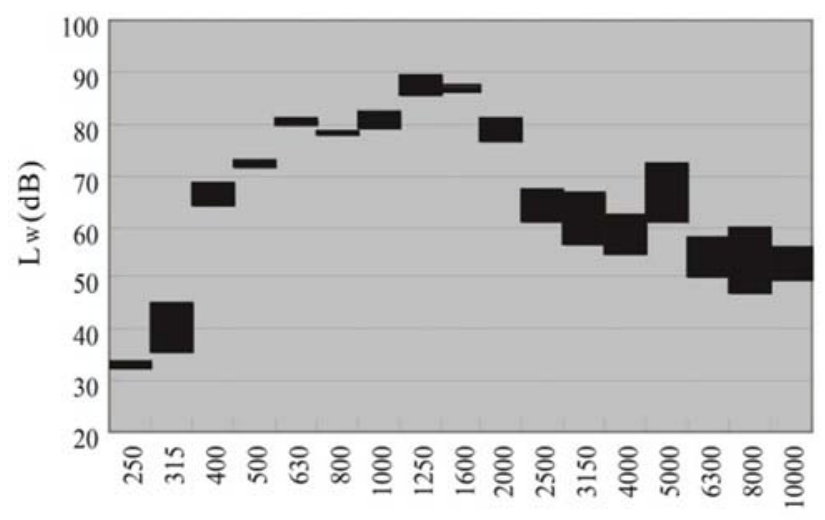

Center frequency of $1 / 3$ octave bands

Figure 8. SWL differences of Qudi I and II when the music scale was performed at pp dynamic.

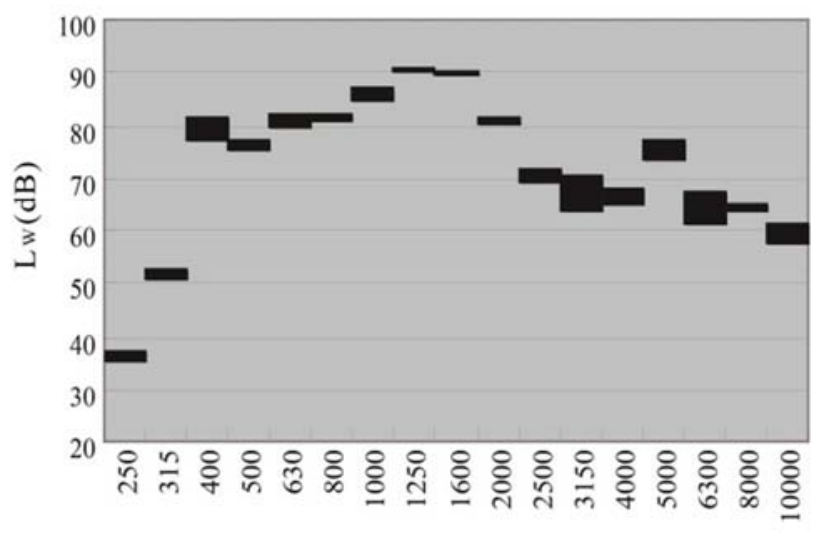

Center frequency of $1 / 3$ octave bands

Figure 9. SWL differences of Qudi I and II when the music scale was performed at mp dynamic.

Figures 8, 9, 10 and 11 showcase the average SWLs in 1/3 octave bands and their differences when the music scale was performed on Qudi I and II at $p p, m p, f$ and $f f$ dynamics respectively. The sound power differences of two Qudis are relatively larger at $p p$ dynamic while they become fairly smaller at ff dynamic, which proves that the tendencies of sound energy radiated by the two Qudis in each frequency band become more consistent when the dynamic grows stronger.

At $p p$ dynamic, it is obvious that the SWL differences of two Qudis are smaller in middle frequency bands and relatively larger in high frequency bands. Further exploration shows that the SWL differences are within $3.1 \mathrm{~dB}$ in the middle frequency bands of $500 \sim 1600 \mathrm{~Hz}$, with the minimum difference of $0.1 \mathrm{~dB}$ occurring at $800 \mathrm{~Hz}$. In high frequency bands, relatively larger differences of $10.1 \mathrm{~dB}, 10.9 \mathrm{~dB}$ and $12.9 \mathrm{~dB}$ occur at $3150 \mathrm{~Hz}, 5000 \mathrm{~Hz}$ and $8000 \mathrm{~Hz}$ respectively; meanwhile, other differences in high frequency bands are greater than $6.3 \mathrm{~dB}$. 


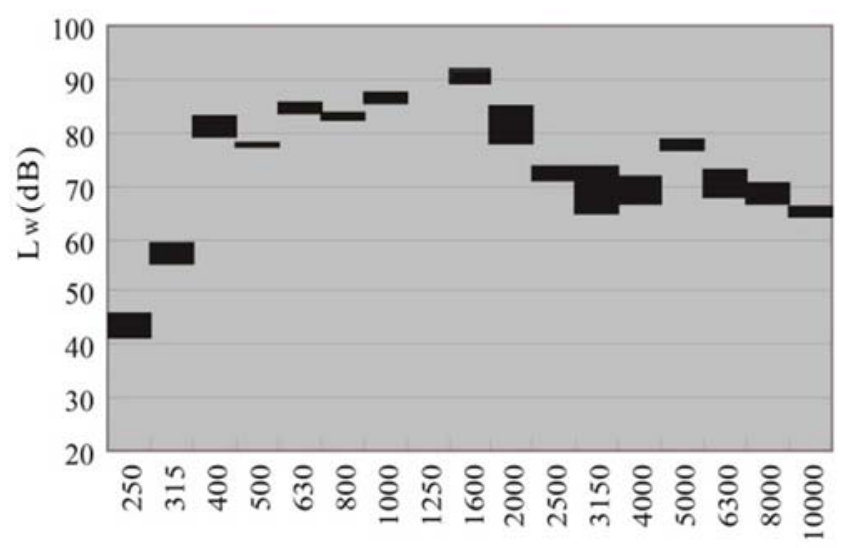

Center frequency of $1 / 3$ octave bands

Figure 10. SWL differences of Qudi I and II when the music scale was performed at $f$ dynamic.

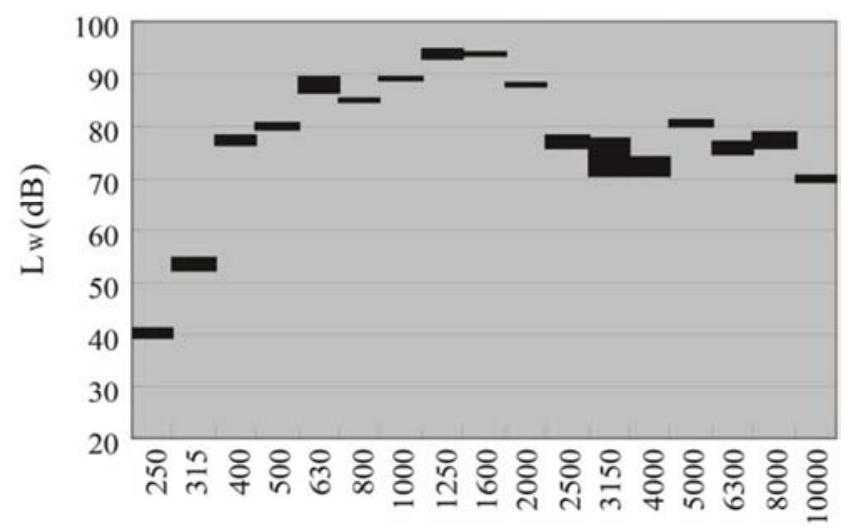

Center frequency of $1 / 3$ octave bands

Figure 11. SWL differences of Qudi I and II when the music scale was performed at ff dynamic.

At $m p$ dynamic and in low and middle frequency bands of $250 \sim 2500 \mathrm{~Hz}$, the SWL differences of the two Qudis are smaller than $2.8 \mathrm{~dB}$, and the minimum difference of $0.3 \mathrm{~dB}$ appears at $1600 \mathrm{~Hz}$, except for a $4.6 \mathrm{~dB}$ difference occurring at $400 \mathrm{~Hz}$. Even in the high frequency bands, the differences of SWL are lower than $3.6 \mathrm{~dB}$, except for the 6.9 and $6.3 \mathrm{Db}$ differences at $3150 \mathrm{~Hz}$ and $6300 \mathrm{~Hz}$ respectively.

At $f$ dynamic, the SWL differences of the two Qudis are less than $5.2 \mathrm{~dB}$ in the whole $1 / 3$ octave bands, except for relatively bigger differences of $9.0 \mathrm{~dB}$ and $7.2 \mathrm{~dB}$ at $3150 \mathrm{~Hz}$ and $2000 \mathrm{~Hz}$ respectively. Amongst, in the middle frequency bands of $500 \sim 1600 \mathrm{~Hz}$ in $1 / 3$ octave bands, the differences of SWL are less than $2.9 \mathrm{~dB}$, and the minimum difference of $0.6 \mathrm{~dB}$ occurs at $500 \mathrm{~Hz}$.

At ff dynamic, the SWL differences of the two Qudis are less than $3.4 \mathrm{~dB}$ at the frequency bands of $250 \sim 2500 \mathrm{~Hz}$ in $1 / 3$ octave bands, while the differences of $0.6 \mathrm{~dB}, 0.8 \mathrm{~dB}$ and $0.7 \mathrm{~dB}$ occur at $1000 \mathrm{~Hz}, 1600 \mathrm{~Hz}$ and $2000 \mathrm{~Hz}$ respectively. At high frequency bands, the smaller differences of $0.9 \mathrm{~dB}$ and $0.8 \mathrm{~dB}$ appear at $5000 \mathrm{~Hz}$ and $10000 \mathrm{~Hz}$ respectively, while the maximum difference between the two Qudis is $6.9 \mathrm{~dB}$ at $3150 \mathrm{~Hz}$.

It was reported that the Lpf in a hall is strongly correlated with the sound quality feelings such as subjective feelings of sound and space at forte dynamic [14], therefore the Lwf (SWL at $f$ dynamic) is the most essential and representative to musical instruments. The SWL spectra when the music scale was performed can comprehensively display the sound energy radiated by the musical instruments in various frequency bands.

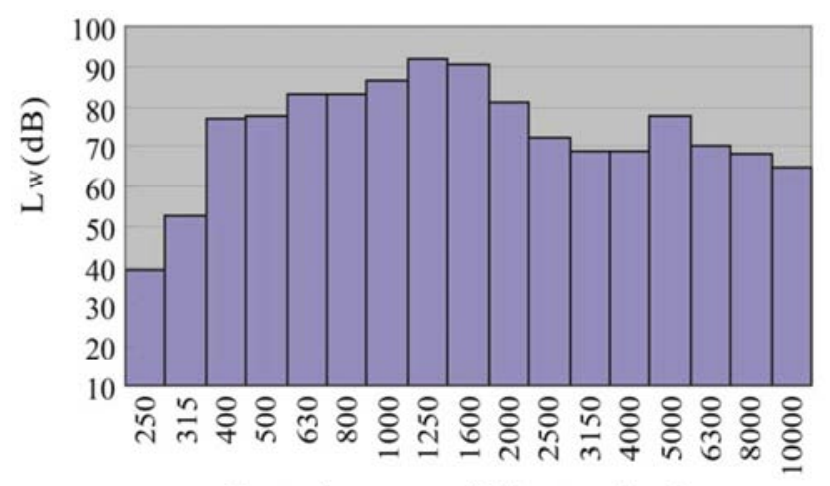

Center frequency of $1 / 3$ octave bands

Figure 12. SWL spectra of Qudi I and II when the music scale was performed at $f$ dynamic.

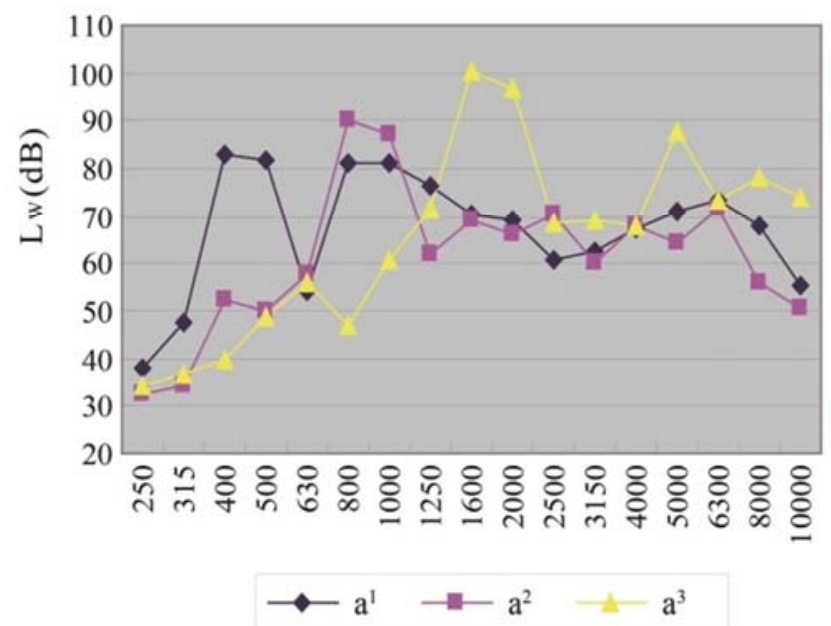

Figure 13. SWL spectra in $1 / 3$ octave bands of Qudi I when three single notes performed at $f$ dynamic.

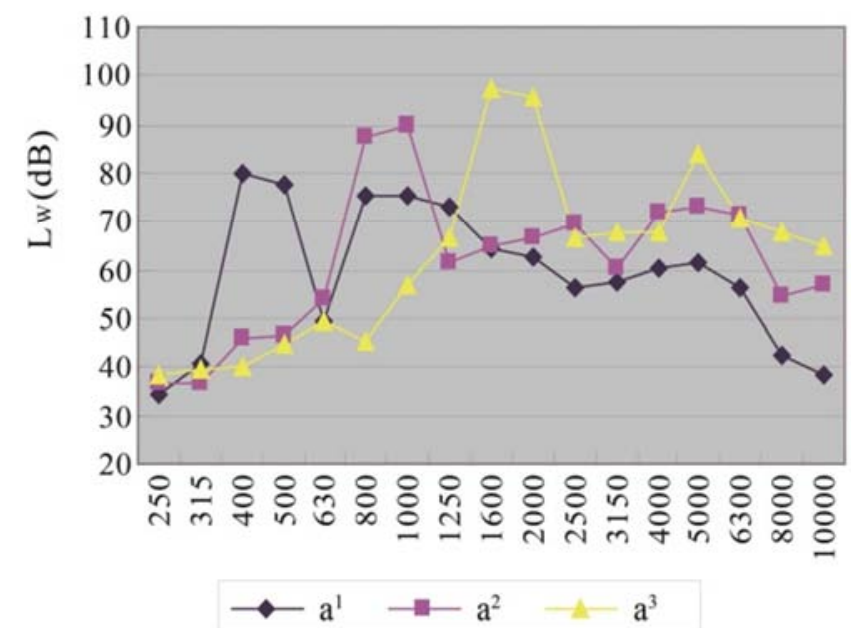

Figure 14. SWL spectra in $1 / 3$ octave bands of Qudi II when three single notes performed at $f$ dynamic. 
Figure 12 shows the average SWL spectra in $1 / 3$ octave bands when the music scale was performed at $f$ dynamic on Qudi I and II. It indicates the higher levels appear in broad frequency bands of $630 \mathrm{~Hz} 2000 \mathrm{~Hz}$, and the SWLs are between $81.3 \mathrm{~dB}$ and $92.1 \mathrm{~dB}$ with all the average value above $80.0 \mathrm{~dB}$

As is mentioned above, the corresponding frequencies for single notes $\mathrm{a}^{1}, \mathrm{a}^{2}$ and $\mathrm{a}^{3}$ are $440 \mathrm{~Hz}, 880 \mathrm{~Hz}$ and $1760 \mathrm{~Hz}$ respectively in $1 / 3$ octave bands. Figures 13 and 14 demonstrate the SWLs in $1 / 3$ octave bands when single notes were performed on the two Qudis at $f$ dynamic.

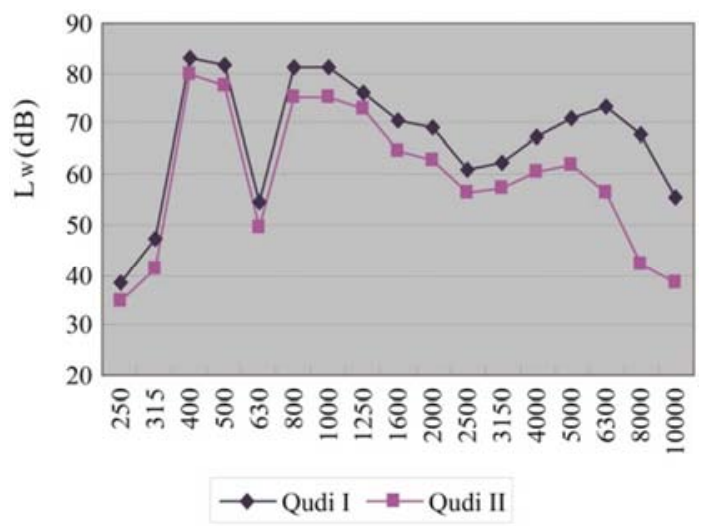

Figure 15. SWL spectra comparison of Qudi I and II when the note $a^{l}$ was performed at $f$ dynamic.

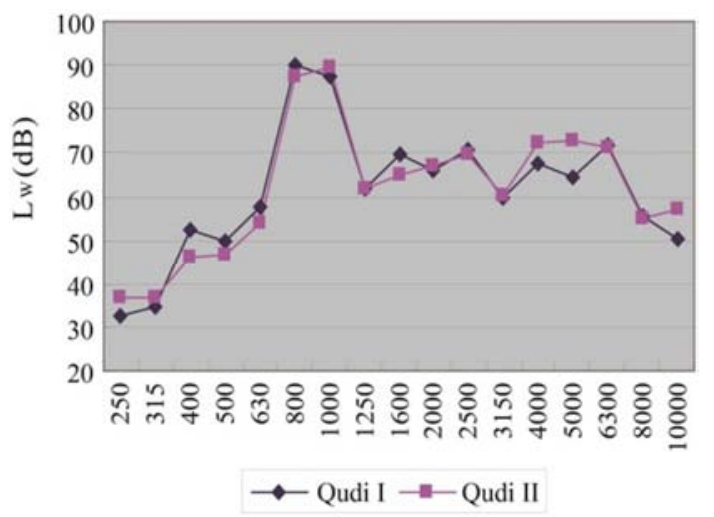

Figure 16. SWL spectra comparison of Qudi I and II when the note $a^{2}$ was performed at $f$ dynamic.

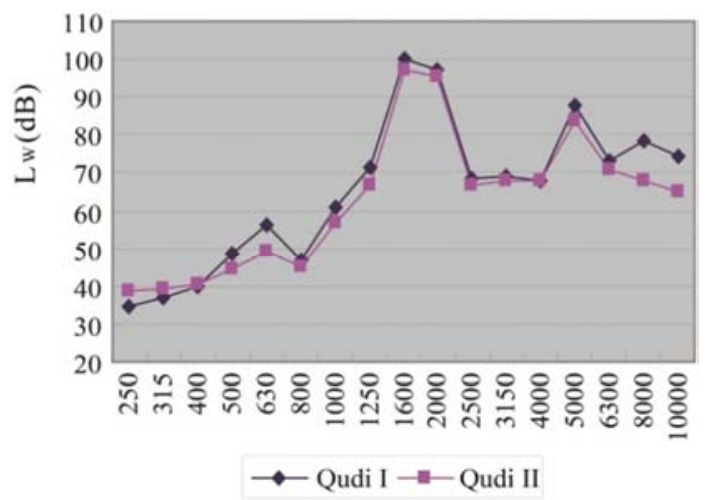

Figure 17. SWL spectra comparison of Qudi I and II when the note $a^{3}$ was performed at $f$ dynamic.
Figures 15, 16 and 17 present the SWLs when three single notes were performed on Qudi I and II at $f$ dynamic.

When the note $\mathrm{a}^{1}$ was performed, in the broad frequency bands of 250 4000Hz, the differences of SWL between Qudi I and Qudi II are between 3.1 7.0dB.

When the note $\mathrm{a}^{2}$ was performed, the maximum SWL appears at $800 \mathrm{~Hz}$ and $1000 \mathrm{~Hz}$ for Qudi I and Qudi II respectively.

The chart tendency of note $\mathrm{a}^{3}$ is similar to that of $\mathrm{a}^{2}$, while the peak SWL appears at $1600 \mathrm{~Hz}$ and $2000 \mathrm{~Hz}$ respectively.

\section{Conclusion}

The following conclusions can be drawn in accordance with the analysis based on the Qudi measurement data:

1. The SWLs of Qudi generally maintain in a high level. At ff dynamic, the maximum SWL of $104.6 \mathrm{~dB}$ occurred when the note $\mathrm{a}^{3}$ (in soprano range) was performed on Qudi I; while at $p p$ dynamic, the minimum SWL of $78.8 \mathrm{~dB}$ appeared when the note $\mathrm{a}^{1}$ (in bass range) was performed on Qudi I.

2. The SWL dynamic range of Qudi is not wide. The minimum dynamic range of $3.1 \mathrm{~dB}$ occurred when the note $\mathrm{a}^{1}$ was performed on Qudi II, which presents a relatively smaller dynamic range from $3.1 \mathrm{~dB}$ to $7.6 \mathrm{~dB}$ in all measurement contents; compared with Qudi II, Qudi I demonstrates a larger dynamic range from $7.1 \mathrm{~dB}$ to $13.6 \mathrm{~dB}$ in all measurements. Qudi presented relatively narrower dynamic ranges than other two types of Chinese traditional musical instruments, string and strum musical instruments.

3. The measurement of the music scale proves that the energy radiated by Qudi has a greater contribution above $400 \mathrm{~Hz}$ in $1 / 3$ octave bands, which means Qudi's main sound range is alto and soprano.

4. In the middle frequency bands above $2500 \mathrm{~Hz}$, the energy of the instrument decays in increasingly rapid speed as the dynamic lowers.

5. Considering the important role of Lpf in the research of hall acoustics, we suggest to use the SWL when the music scale is performed at $\mathrm{f}$ dynamic as the representative SWL of Qudi [15]. In this measurement, the average SWL of the two Qudis at $f$ dynamic is 96.2 dB.

The systematic SWL measurement results of national musical instruments are not only of great significance to Chinese traditional musical instruments' study, but also important to the study on staffing and composition of native orchestra, performing forms, and hall of traditional music and opera. Meanwhile, it also provides references to the study on other countries and nations' wind instruments.

\section{Acknowledgements}

This work was supported by the National Natural Science Foundation of China (no. 50178030) and by the National Natural Science Foundation of Guangdong Province, China 
(no. 011668). The authors are grateful to the musicians attended this study for their professional performance.

\section{References}

[1] Museum H. Three National treasures from Henan Museum to appear in «National Treasure» [EB/OL]. [2017-12-15]. http://www.chnmus.net/sitesources/hnsbwy/page pc/wbzx/yn $\mathrm{dt} /$ article5253bablc1b84dd59adeba4d01f016de.html. (in Chinese)

[2] Clark M, Luce D. Intensities of Orchestral Instrument Scales Played at Prescribed Dynamic Markings [J]. Journal of the Audio Engineering Society, 1965, 13 (2): 151-157.

[3] Meyer J. Zur Dynamik und Schalleistung von Orchesterinstrumenten [J]. Acta Acustica united with Acustica, 1990, 71 (4): 277-286.

[4] Meyer J. Raumakustik Und Orchesterklang in Den Konzertsaelen Joseph Haydns. [J]. Acustica, 1978, 41 (3): $145-162$.

[5] Kuhl W. Raeumlichkeit Als Komponente Des Raumeindrucks. [J]. Acustica, 1978, 40 (3): 167-181.

[6] Lehmann P. Über die Ermittlung raumakustischer Kriterien und deren Zusammenhang mit subjektiven Beurteilungen der Hörsamkeit [J]. Dissertation, 1976.

[7] Meyer J, Angster J. Zur Schalleistungsmessung Bei Violinen. [J]. Acustica, 1981, 49 (3): 192-204.
[8] Wu S X, Zhao Y Z, Qiu J Z, et al. Sound power level measurement of the Erhu (Chinese violin)[J]. Acta Acustica united with Acustica, 2008, 94 (1): 164-167.

[9] Zhao Y Z, Wu S X, Qiu J Z, et al. Sound intensity radiated by Gaohu [J]. Science China Technological Sciences, 2010, 53 (7): 1792-1797.

[10] Zhao Y Z, Wu S X, Qiu J Z, et al. Sound power level measurement for Chinese plucked stringed instrument Liuqin [J]. Journal of Tianjin University. 2010, 43 (1): 71-76.(In Chinese).

[11] Zhao Y Z, Wu S X, Qiu J Z, et al. Sound Power Level Measurement of Zhonghu, a Chinese Bowed Instrument. TEMPORAL DES. ARCH. ENVIRON. 2009. http://www.jtdweb.org

[12] Qiu J Z, Wu S X. Architectural acoustics laboratory of Sound China University of Technology [C]//International Congress and Exposition on Noise Control Engineering 32nd. 2003: 1526-1531.

[13] Bouhuys A. Sound-Power Production in Wind Instruments [J]. Journal of the Acoustical Society of America, 1965, 37 (3): 453-456.

[14] Qiu J Z, Wu S X. Preferable loudness value for Chinese native music $[\mathrm{J}]$. Huanan Ligong Daxue Xuebao/Journal of South China University of Technology (Natural Science), 2007, 35 (SUPPL.): 64-67.

[15] Wu S X, Li Q M, Kittinger E. A new criterion for concert hall loudness evaluation $[\mathrm{J}]$. Acta Acustica united with Acustica, 2001, 87 (2): 286-289. 